\title{
A 30-day prospective audit of all inpatient complications following acute care surgery: How well do we really perform?
}

\author{
Chad G. Ball, MD, MSc \\ Patrick Murphy, MD \\ Kevin Verhoeff, MD \\ Omar Albusadi, MD \\ Matthew Patterson, MD \\ Sandy Widder, MD \\ S. Morad Hameed, MD, MPH \\ Neil Parry, MD \\ Kelly Vogt, MD \\ John B. Kortbeek, MD \\ Anthony R. MacLean, MD \\ Paul T. Engels, MD \\ Timothy Rice, MD \\ Rahima Nenshi, MD \\ Kosar Khwaja, MD \\ Samuel Minor, MD \\ on behalf of the Canadian \\ Collaborative on Urgent Care \\ Surgery (CANUCS)
}

This work was presented at the American College of Surgeons Clinical Congress, Oct. 22, 2018, Boston, Mass.

Accepted Aug. 14, 2019

\section{Correspondence to:}

C.G. Ball

Foothills Medical Centre

1403 - 29 St NW

Calgary $A B$ T2N 2T9

ball.chad@gmail.com

DOI: 10.1503/cjs.019118
Background: Acute care surgery (ACS) and emergency general surgery (EGS) services must provide timely care and intervention for patients who have some of the most challenging needs. Patients treated by ACS services are often critically ill and have both substantial comorbidities and poor physiologic reserve. Despite the widespread implemention of ACS/EGS services across North America, the true postoperative morbidity rates remain largely unknown.

Methods: In this prospective study, inpatients at 8 high-volume ACS/EGS centres in geographically diverse locations in Canada who underwent operative interventions were followed for 30 days or until they were discharged. Readmissions during the 30-day window were also captured. Preoperative, intraoperative and postoperative variables were tracked. Standard statistical methodology was employed.

Results: A total of 601 ACS/EGS patients were followed for up to 30 inpatient or readmission days after their index emergent operation. Fifty-one percent of patients were female, and the median age was 51 years. They frequently had substantial medical comorbidities $(42 \%)$ and morbid obesity (15\%). The majority of procedures were minimally invasive (66\% laparoscopic). Median length of stay was 3.3 days and the early readmission $(<30 \mathrm{~d})$ rate was $6 \%$. Six percent of patients were admitted to the critical care unit. The overall complication and mortality rates were $34 \%$ and $2 \%$, respectively. Cholecystitis $(31 \%)$, appendicitis $(21 \%)$, bowel obstruction (18\%), incarcerated hernia (12\%), gastrointestinal hemorrhage $(7 \%)$ and soft tissue infections $(7 \%)$ were the most common diagnoses. The morbidity and mortality rates for open surgical procedures were $73 \%$ and $5 \%$, respectively.

Conclusion: Nontrauma ACS/EGS procedures are associated with a high postoperative morbidity rate. This study will serve as a prospective benchmark for postoperative complications among ACS/EGS patients and subsequent quality improvement across Canada.

Contexte : Les services de chirurgie dans les unités de soins actifs (CSA) et de chirurgie générale dans les services d'urgence (CGSU) doivent fournir rapidement des soins et des interventions à des patients dont les besoins sont parmi les plus complexes. En effet, les patients pris en charge par les services de CSA sont souvent gravement malades et présentent des comorbidités sur fond de faible réserve physiologique. Même si les services de CSA/CGSU se sont répandus en Amérique du Nord, les taux réels de morbidité postopératoire demeurent pour une bonne part inconnus.

Méthodes : Dans cette étude prospective, on a suivi pendant 30 jours ou jusqu'à leur congé, les patients hospitalisés pour des interventions chirurgicales dans 8 centres de CSA/CGSU achalandés de divers endroits au Canada. On a également tenu compte des réadmissions dans les 30 jours. Les paramètres pré-, per- et postopératoires ont été enregistrés. Une méthodologie statistique standard a été appliquée.

Résultats : En tout, 601 patients de CSA/CGSU ont ainsi été suivis pendant une durée allant jusqu'à 30 jours d'hospitalisation ou de réadmission après leur intervention urgente initiale. Cinquante et un pour cent étaient de sexe féminin et l'âge moyen était de 51 ans. Ces patients étaient nombreux à présenter des comorbidités de nature médicale substantielles (42\%) et une obésité morbide (15\%). La majorité des interventions ont été minimalement effractives (66\% laparoscopiques). La durée médiane des séjours a été de 3,3 jours et le taux de réadmission précoce $(<30$ j) a été de $6 \%$. Six pour cent des patients ont été admis aux soins intensifs. Les taux globaux de complications et de mortalité ont été respectivement de $34 \%$ et de $2 \%$. Cholécystite (31\%), appendicite $(21 \%)$, obstruction intestinale $(18 \%)$, hernie incarcérée $(12 \%)$, hémorragie digestive $(7 \%)$ et infections des tissus mous $(7 \%)$ comptent parmi les diagnostics les plus fréquents. Les taux de morbidité et de mortalité dans les cas de chirurgies ouvertes ont été respectivement de $73 \%$ et $5 \%$.

Conclusion : Les interventions de CSA/CGSU non liées à la traumatologie sont associées à un taux de morbidité postopératoire élevé. Cette étude fournira un ensemble de valeurs de références pour l'étude prospective des complications chez les patients pris en charge par les services de CSA/CGSU et l'amélioration subséquente des soins partout au Canada. 
I $t$ is clear to every surgeon working in acute care surgery (ACS) and emergency general surgery (EGS) that timely and complex surgical care is required to achieve optimal outcomes for a significant proportion of our urgently ill patients. ${ }^{1,2}$ Not surprisingly, postoperative morbidity and mortality remain a dominant source of both patient and surgeon distress. Although postoperative complications are often expected to occur, given that these patients are frequently in critical condition and in an advanced comorbid state (i.e., they have poor physiologic reserve), quality improvements in patient care and health system delivery must continue to be a primary goal for any busy acute care surgery service., ${ }^{3,4}$ Although precise morbidity and mortality rates are commonly reported for oncologic resections, trauma care $^{5}$ and scheduled elective surgical interventions, much less is known about the true incidence of postoperative complications for the ACS/EGS patient population in contemporary service-based care models.

Not only is a granular understanding of postoperative complications among ACS/EGS patients essential for quality metrics, but it is also critical to the creation and delivery of postoperative care pathways for many of the most common ACS/EGS diagnoses. Given the absence of either detailed or comprehensive prospective morbidity and mortality data in the literature, the primary goal of this prospective study was to analyze all 30-day inpatient complications following ACS/EGS operative interventions at multiple high-volume centres.

\section{Methods}

All adult (aged $16 \mathrm{yr}$ and older) patients who were admitted to an ACS/EGS service and subsequently underwent an operative intervention were prospectively audited on a daily basis. The total duration of inpatient follow-up was 30 days or until the patient was discharged home (or to a formal rehabilitation facility). Readmissions within a 30-day window were also captured. This 30- to 59-day study was carried out at various institutions between Jan. 1, 2018, and July 31, 2018 (the specific 30-day window was at the discretion of each individual site). A standardized comprehensive data capture form was used for all sites. Institutional ethics review board approval and formal data-sharing agreements were required for each hospital. Participating centres were the Foothills Medical Centre (Calgary), Rockyview General Hospital (Calgary), London Health Sciences Centre (London), Vancouver General Hospital (Vancouver), University of Alberta Hospital (Edmonton), Montreal General Hospital (Montreal), Hamilton General Hospital, St. Joseph's Healthcare Hamilon (Hamilton) and Queen Elizabeth II Health Sciences Centre (Halifax). Each of these centres is a large university-affiliated teaching hospital offering tertiary care.
We standardized and agreed upon the definitions of all complications before we initiated the study. We used standard definitions from the US Centers for Disease Control and Prevention (CDC) for pneumonia, bloodstream infections, urinary tract infections and surgical site infections (both superficial and deep). Definitions for acute kidney injury (abrupt $[<48 \mathrm{~h}]$ reduction in kidney function, defined as an absolute increase in serum creatinine $\geq 26.4 \mu \mathrm{mol} / \mathrm{L}, \mathrm{a}>50 \%$ increase in serum creatinine or a reduction in urine output $<0.5 \mathrm{~mL} / \mathrm{kg} / \mathrm{h}$ for more than $6 \mathrm{~h}$ ), wound disruption (fascial or skin dehiscence), gastrointestinal anastamotic leakage (confirmed on crosssectional imaging or fistulogram or evidence on reintervention), deep venous thrombosis or pulmonary embolus (confirmed by imaging), prolonged ileus (lack of clinical bowel activity beyond the expected time frame), gastrointestinal or intraperitoneal hemorrhage, and organ failure were consistent across all study patients. Demographic, disease and operative characteristics were also evaluated for the study patients.

Data are presented as means or medians where appropriate using descriptive statistics. Differences in patient data and secondary measures between patient groups were assessed using a $\chi^{2}$ analysis and Student $t$ tests for categorical and scale data, respectively. An $\alpha$ significance level of 0.05 was set a priori. All statistical testing was performed using Stata/IC version 15.0 (Stata Corp.).

\section{Results}

Among the 8 participating centres, 601 patients (range 52-96 patients per site) were prospectively audited following an operative intervention. Patient characteristics were remarkably consistent across all sites (Table 1) $(p>$ $0.05)$. Only the rate of obesity varied significantly among hospitals $(2 \%-26 \%)(p<0.05)$. Diagnoses across sites were also similar (Table 1$)(p>0.05)$. Across all sites, operative techniques were primarily laparoscopic (i.e., laparoscopic cholecystectomy and appendectomy ranging from $14 \%$ to $43 \%[p<0.05]$ and from $5 \%$ to $28 \%[p<0.05]$ of total operative cases, respectively). The remaining laparoscopic cases included bowel obstruction (lysis or release) (8\%), hernia repair $(6 \%)$, diagnostic endeavours (2\%) and common bile duct exploration (1\%).

Table 2 outlines patient outcomes. Hospital performance across sites was similar in terms of postoperative complications $(p>0.05)$. Superficial (wound) locations comprised $69 \%$ of surgical site infections. Patients who underwent laparoscopic procedures experienced less postoperative morbidity than those who underwent open surgical procedures $(p<0.05)$. Among the 204 patients who underwent open procedures, complication and mortality rates approximated $73 \%$ and $5 \%$, respectively $(p<0.05)$. 


\section{Discussion}

Although the postoperative mortality rate among patients on ACS/EGS services across the high-volume centres particpating in this study was only $2 \%$, morbidity was substantial (34\%). This observation confirms a report

\begin{tabular}{|c|c|}
\hline Characteristic & $\%$ of patients* \\
\hline Age, median, yr & 51 \\
\hline Sex, female & 51 \\
\hline ASA score, mean & 2 \\
\hline Morbid obesity & 15 \\
\hline Substantial medical comorbidities† & 42 \\
\hline \multicolumn{2}{|l|}{ Final diagnosis } \\
\hline Cholecystitis & 31 \\
\hline Appendicitis & 21 \\
\hline Bowel obstruction & 18 \\
\hline Incarcerated hernia & 12 \\
\hline Gastrointestinal hemorrhage & 7 \\
\hline Soft tissue infections & 7 \\
\hline Other & 4 \\
\hline \multicolumn{2}{|l|}{ Procedure } \\
\hline Laparoscopic technique & 66 \\
\hline Laparoscopic cholecystectomy & 30 \\
\hline Laparoscopic appendectomy & 19 \\
\hline Other laparoscopy & 17 \\
\hline \multicolumn{2}{|c|}{$\begin{array}{l}\text { ASA }=\text { American Society of Anesthesiologists preoperative risk assessment score. } \\
{ }^{*} \text { Unless indicated otherwise. } \\
\text { †Medical comorbidities that require chronic treatment. }\end{array}$} \\
\hline
\end{tabular}

Table 2. Patient outcomes following surgical intervention

\begin{tabular}{|lc|}
\hline Outcome & \% of patients* \\
\hline Intensive care unit admission & 6 \\
\hline Hospital length of stay, median, d & 3 \\
\hline Early readmission (<30 d) & 6 \\
\hline Overall mortality & 2 \\
\hline Overall morbidity & 34 \\
\hline Prolonged ileus & 24 \\
\hline Surgical site infections & 13 \\
\hline Superficial (wound) & 9 \\
\hline Deep (organ space) & 4 \\
\hline Aspiration (including aspiration pneumonia) & 8 \\
\hline Hematoma & 5 \\
\hline Delirium & 4 \\
\hline Gastrointestinal hemorrhage & 4 \\
\hline Urinary tract infection & 4 \\
\hline Major cardiac events & 4 \\
\hline Poor postoperative analgesia & 2 \\
\hline Clostridium difficile colitis & 2 \\
\hline Deep venous thrombosis & 2 \\
\hline Pulmonary embolus & 1 \\
\hline Other & 4 \\
\hline *Unless indicated otherwise. & \\
\hline
\end{tabular}

based on retrospective data from the National Surgical Quality Improvement Program (NSQIP) that highlighted a $33 \%$ postoperative morbidity rate. ${ }^{6}$ When we excluded laparoscopic cases and evaluated open surgical interventions in isolation, the complication rate increased to $73 \%$, and the mortality rate was $5 \%$. Given the high complication rates we observed across centres of excellence, hospitals and health care systems that are willing to offer emergency on-call general surgical services must also contemplate both the associated financial costs and the resource implications of treating very ill patients with comorbidities. More specifically, ACS/EGS services must be appropriately resourced in all relevant areas to ensure timely and adequate patient care. Critical resources include urgent access to the operating theatre, adequate staffing for patient care (which may include nurse practitioners, physician assistants and resident house staff, depending on the site), focused coverage by attending surgeons that is also appropriately remunerated, and an acute pain service. Given that most ACS/EGS patients will need to be admitted to hospital, a dedicated inpatient ward within a single geographic location is also essential for these patients. Although patients with diagnoses other than cholecystitis and appendicitis who required open surgical procedures represent the minority of total cases $(34 \%)$, it is clear that their resource requirements are even higher than those of ACS/EGS patients who undergo laparoscopic procedures.

Although it is critical to have adequate resources to ensure safe and excellent patient care for the ACS/EGS population, it is also essential to improve quality and overall outcomes for these patients. In particular, tools such as the NSQIP are available both inside and outside of the United States. ${ }^{7}$ Despite their substantial upfront financial cost, these aids allow both internal and external benchmark comparisons to be made using standardized definitions of diagnoses and subsequent complications. As indicated in many publications, ${ }^{8-12}$ the financial and patient costs of postoperative complications remain substantial and concerning.

It is interesting to note that approximately two-thirds of all cases on busy ACS/EGS services used laparoscopy. Although the vast majority of these procedures were cholecystectomy and appendectomy, application of this methodology to other conditions (bowel obstructions, hernias) was also observed. Despite the preceding debate on the role of traditional open appendectomy in the literature, nearly all patients with appendicitis in our study underwent a laparoscopic procedure. The benefits of minimally invasive methodologies are clear, and it is encouraging that the rates of laparoscopic appendectomy are increasing over time compared with the rates reported in previous national publications. ${ }^{13-16}$

Although an ACS/EGS service in a busy hospital typically treats patients with a wide range of diagnoses using a 
broad series of interventions, surgical procedures typically cluster around laparoscopic cholecystectomy, laparoscopic appendectomy, release of bowel obstructions, reduction of incarcerated hernias, arrest of gastrointestinal hemorrhage and drainage and débridement of soft tissue infections. These "big 6" procedures also represent the greatest opportunities for quality improvement. For example, many patients with acute appendicitis can now be treated and released from hospital in less than 24 hours as long as rapid access to the operating theatre and programmatic fast track are available. ${ }^{17,18}$

\section{Limitations}

There are 3 main limitations of this project. First, data collection was limited to centres that expressed an interest in participating; therefore, as in earlier studies, ${ }^{19}$ the possibility of participation bias cannot be eliminated. Given the relative similarity of the findings of the present study to those of a large retrospective national database study, however ${ }^{6}$ it is probable that these data apply well beyond the 8 participating centres. Second, although this study included several centres from across a large country (Canada), smaller community hospitals may treat a very different case mix in regard to patient illness severity and required surgical procedures. As a result, this could limit the generalizability of these results to hospitals in more remote areas of Canada that continue to provide EGS care. Third, despite the importance of formal surgical rescue $^{20}$ in determining the mortality rate following patient complications, our national group was unable to reliably capture these data across all centres. We postulate that given the fact that the participating centres were academic tertiary care hospitals, however, the low reported mortality rate $(2 \%)$ indirectly indicates reasonably good surgical rescue efforts for patients with significant postoperative complications.

\section{Conclusion}

Up to $34 \%$ of patients requiring an emergent surgical procedure in the context of a formal ACS/EGS service will experience a postoperative complication. Among patients who underwent an open surgical procedure, this rate increased to $73 \%$ in our study. Given the substantial medical comorbidities and severe illness that many of these patients experience, appropriate hospital system resourcing and structured attempts at quality improvement are essential.

Acknowledgements: The authors acknowledge Julian Wang and Tyler McKenzie for their assistance with data collection.

Affiliations: From the Department of Surgery, Cumming School of Medicine, University of Calgary, Calgary, Alta. (Ball, Albusadi, Patterson, Kortbeek, MacLean); Western University, London, Ont. (Murphy, Parry, Vogt); the University of Alberta, Edmonton, Alta. (Verhoeff,
Widder); the University of British Columbia, Vancouver, B.C. (Hameed); McMaster University, Hamilton, Ont. (Engels, Rice, Nenshi); McGill University, Montréal, Que. (Khwaja); and Dalhousie University, Halifax, N.S. (Minor).

Competing interests: Anthony MacLean received a stipend to serve as a faculty member at an Ethicon colorectal surgery bootcamp for the Canadian colorectal surgery fellows. No other competing interests were declared.

Contributors: C. Ball, P. Murphy, O. Albusadi, S. Hameed, N. Parry, K. Vogt, J. Kortbeek, A. MacLean designed the study. C. Ball, P. Murphy, K. Verhoeff, O. Albusadi, M. Patterson, S. Widder, K. Vogt, P. Engels, T. Rice, R. Nenshi, K. Khwaja and S. Minor acquired the data, which C. Ball, P. Murphy, K. Vogt, J. Kortbeek, A. MacLean analyzed. C. Ball, P. Murphy, M. Patterson wrote the article, which C. Ball, P. Murphy, K. Verhoeff, O. Albusadi, S. Widder, S. Hameed, N. Parry, K. Vogt, J. Kortbeek, A. MacLean, P. Engels, T. Rice, R. Nenshi, K. Khwaja and S. Minor critically reviewed. All authors approved the article for publication.

CANUCS members: The Canadian Collaborative on Urgent Care Surgery consists of the individuals listed as authors of this article.

\section{References}

1. Hameed SM, Brenneman FD, Ball CG, et al. General surgery 2.0: the emergence of acute care surgery in Canada. Can 7 Surg 2010;53:79-83.

2. Ball CG, Hameed SM, Brenneman FD. Acute care surgery: a new strategy for the general surgery patients left behind. Can $\mathcal{F}$ Surg 2010;53:84-5.

3. Ball CG, MacLean AR, Dixon E, et al. Acute care surgery: the impact of an acute care surgery service on assessment, flow, and disposition in the emergency department. Am f Surg 2012;203:578-83.

4. Johner AM, Merchant S, Aslani N, et al. Acute general surgery in Canada: a survey of current handover practices. Can 7 Surg 2013;56:E24-8.

5. Ball CG, Das D, Roberts DJ, et al. The evolution of trauma surgery at a high-volume Canadian centre: implications for public health, prevention, clinical care, education and recruitment. Can 7 Surg 2015;58:19-23.

6. Havens JM, Peetz AB, Do WS, et al. The excess morbidity and mortality of emergency general surgery. 7 Trauma Acute Care Surg 2015;78:306-11.

7. Guillamondegui OD, Gunter OL, Hines L, et al. Using the National Surgical Quality Improvement Program and the Tennessee Surgical Quality Collaborative to improve surgical outcomes. 7 Am Coll Surg 2012;214:709-16.

8. Renz BM, Feliciano DV. Unnecessary laparotomies for trauma: a prospective study of mortality. 7 Trauma 1995;38:350-6.

9. Bandy NL, Britt RC, DeShields SC, et al. Acute diverticulitis outcomes in the acute care surgery model. 7 Am Coll Surg 2018;226:623-7.

10. Li T, Robertson-More C, MacLean AR, et al. Bowel obstructions and incisional hernias following trauma laparotomy and the nonoperative therapy of solid organ injures: a retrospective population-based analysis. 7 Trauma Acute Care Surg 2015;79:568-79.

11. Murphy PBV, DeGirolamo K, Van Zyl TJ, et al. Meta-analysis on the impact of the acute care surgery model of disease and patient specific outcomes in appendicitis and biliary disease. 7 Am Coll Surg 2017;225:763-77.

12. Narayan M, Tesoriero R, Bruns BR, et al. Acute care surgery: defining the economic burden of emergency general surgery. $7 \mathrm{Am}$ Coll Surg 2016;222:691-9. 
13. Blackmore C, Tanyingo D, Kaplan GG, et al. A comparison of outcomes between laparoscopic and open appendectomy in Canada. Can 7 Surg 2015;58:431-2.

14. Coward S, Kareemi H, Clement F, et al. Incidence of appendicitis over time: a comparative analysis of an administrative healthcare database and a pathology-proven appendicitis registry. PLoS One 2016;11:e0165161.

15. Ferris M, Quan S, Kaplan BS, et al. The global incidence of appendicitis: a systematic review of population-based studies. Ann Surg 2017;266:237-41.

16. Ball CG, Kortbeek JB, Kirkpatrick AW, et al. Laparoscopic appendectomy for complicated appendicitis: an evaluation of postoperative factors. Surg Endosc 2004;18:969-73.
17. Ball CG, Dixon E, MacLean AR, et al. The impact of an acute care surgery clinical care pathway for suspected appendicitis on the use of CT in the emergency department. Can 7 Surg 2014; 57:194-8.

18. Rosen DR, Inaba K, Oh PJ, et al. Outpatient laparoscopic appendectomy: Feasible in a public county hospital? I Am Coll Surg 2017;Pii: S1072-7515(17)30181-3.

19. DeGirolamo K, D'Souza K, Apte S, et al. A day in the life of emergency general surgery in Canada: a multicenter observational study. Can 7 Surg 2018;61:237-43.

20. Metcalfe D, Castillo-Angeles M, Olufajo OA, et al. Failure to rescue and disparities in emergency general surgery. 7 Surg Res 2018; 231:62-8. 